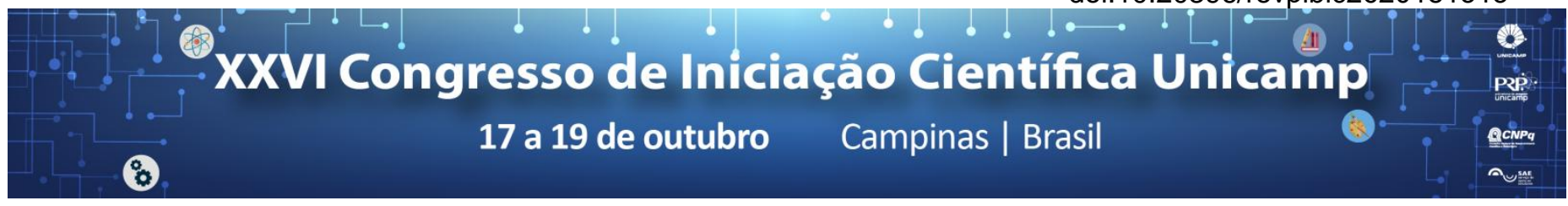

\title{
Comparative Analysis of technologies and types of energy matrices used in Brazil, the United States, and Europe.
}

\section{Thiago Allegretti Artioli, Juliana Aparecida Fracarolli}

\begin{abstract}
The evolution and increase of energy demand has been one of the main impasses found in the present world stage. Thus, this paper aims to study the possible solutions which are being, or may be, used by nations with great potential in the sector, in order to identify a tendency of energy matrices to be used and technologies to be implemented in order to increase the efficiency of the process and sustainability.
\end{abstract}

\section{Keywords:}

Renewable sources, Cogeneration, Sustainability

\section{Introduction}

The project aims to establish an in-depth analysis of the energy behavior of the studied nations, in order to make it possible to obtain a possible tendency, being it regarding the energy matrices, deepening, mainly, the study regarding renewable sources used by each nation, as to the employed thermodynamic cycles.

\section{Results and Discussion}

Image 1. Percentual representativity of the participation of renewable matrices on energy production in Brazil, the United States, and in Eurozone countries in the years 2014 and 2015

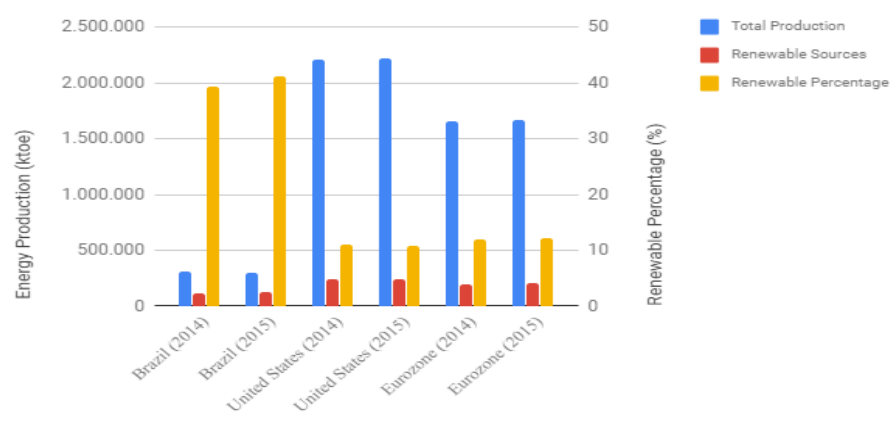

Source: EIA, EUROSTAT and Ministry of Mines and Energy

The high percentages obtained for Brazil were attributed to the representativity growth, in 2015, of sugarcane bagasse, which was equivalent to $41.1 \%$ of the primary energy generation, and wind energy, which presented a growth rate of $77.2 \%$ in the electric energy production.

As for the United States, although they did not present a significant growth in the use of renewable matrices in 2015 , keeping the same $11 \%$, the relevance of sources such as biomass, hydric, solar, and wind energy can be highlighted, with the latter two presenting a growth rate of $26.3 \%$ and $2.5 \%$, respectively.

The Eurozone countries, led by Germany and Italy in the use of renewable sources, presented a general growth rate, in that sector, of $4 \%$, given the increase of the use of matrices such as biomass, solar, and wind.
Image 2. Increase of the use of wind energy to generate electricity in Brazil, the United States, and the Eurozone countries in the period between 2013 and 2016

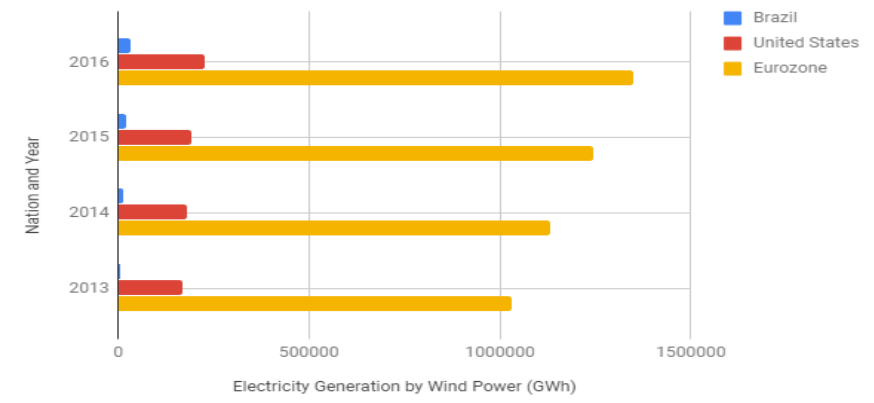

Source: EIA, EUROSTAT and Ministry of Mines and Energy

The performed analysis related to the thermodynamic cycles and the technologies which have been used for energy generation show that, although there is a large quantity of cycles which can be used in the process, cogeneration is the most used, given its higher associated yield, due to its passage through zones of high and low pressure in the turbine.

\section{Conclusions}

Although there are many technologies and matrix possibilities to be employed, there is a notorious tendency from nations such as Brazil, the United States, and the Eurozone countries to replace non-renewable sources matrices, above all wind and biomass, and of the cogeneration cycle, for ensuring higher efficiency in the energy generation process.

\section{Acknowledgement}

I'm deeply thankful to PIBIC, for encouraging this research, and to my family, teachers, and friends for the unconditional support, and to God for always being with me unconditionally on my way.

U.S. ENERGY INFORMATION ADMINISTRATION. Monthly Energy Review, Washington, DC, december.2017

EUROSTAT. Energy Balance Sheets, Luxemburgo, Luxemburgo, july.2017 MINISTÉRIO DE MINAS E ENERGIA. Resenha Energética Brasileira 2015, Brasília, DF, may.2016 